\title{
Austerity, socioeconomic inequalities and stalling life expectancy in the UK: two parallel stories or one?
}

\section{May you live in interesting times (Chinese proverb)}

Undoubtedly, we live in interesting times. The 2008 economic crisis and feeble recovery from it, regional wars, global inequalities, international migration flows and subsequent political changes have changed our world in quite a dramatic way. One of the major changes many European countries have experienced in the 2010s is a slowdown in life expectancy improvement.[1] The decades-long steady improvement in life expectancy in the western world seems no longer to be the case. An extreme example is the USA, where life expectancy declined over three consecutive years between 2014 and 2017.[2,3]

In England and Wales, there is now realisation that improvements in mortality and life expectancy have slowed down or come to a halt.[4-6] The Office for National Statistics (ONS) estimates that between 2011 and 2017 the rate of decline in mortality weakened by $85 \%$ in men and $95 \%$ in women in England,[6] while between 2014 and 2016 life expectancy stalled in both men and women in England. [7] On the basis of these data, the latest (updated) projection is that more than a million deaths will occur earlier than expected over the next 40 years.[8,9] This is one of the greatest slowdowns in life expectancy and mortality improvements observed in both men and women in England and Wales since 1890. $[6,10]$ The emerging increase in mortality in 2018 and prospect of further worsening of the longterm life expectancy trend leave little room for optimism.[11]

Despite disagreement regarding the underlying causes, it now seems apparent that this unprecedented slowdown in life expectancy in the UK is a longer-term change rather than a short-term irregularity.[8,11,12] It is also clear that for the period 2011-15 the UK had the second lowest increase in life expectancy in men and the lowest in women among 25 EU countries. [4] The UK was also the only country, among 20 European countries that experienced a spike in mortality in 2015, where life expectancy did not improve in 2016.[1,2] Another point that most analysts agree is that the slowdown in the life expectancy between 2011 and 2016 refers more to people ages $\geq 65$ years, with women being more affected than men.[1,2,10,12] It should be noted though that it is the first time since at least 1986 that infant mortality increased in two consecutive years, 2015 and 2016; a troubling new development $[13,14]$

Another parallel reality is that of massive socioeconomic inequalities in life expectancy. The UK has experienced a steady improvement in life expectancy for decades before 2011, but these improvements were not distributed equally among social classes. In fact, they were distributed very unequally.[15] For the period 2013-15, men in the most affluent decile of the Index of Multiple Deprivation (IMD), a measure of area-based deprivation, were expected to live 9.1 years more than men in the most deprived decile of IMD, while the same figure in women is 7.2 years. The differences in healthy life expectancy by IMD deciles are even more astonishing. Men in the most affluent IMD decile were expected to live free of disease and disability 18.7 years more than men in the most deprived decile, while the same figure for women was 19.1 years. The picture gets grimmer considering that some of these inequalities are getting wider over time.[16,17]

Many views have been offered about what might be the causes of the slowdown in life expectancy in the UK. $[6,10,18]$ The ensuing debate revolves around two main explanations: this of excess winter mortality $[1,12]$ and that of social causes and austerity. $[4,10,19]$ Winter outbreaks of flu and winter 
excess mortality may be a partial explanation,[12] but it is unlikely that they are the main drivers of a slowdown in life expectancy that spans eight years (2011-18). Flu epidemics involving common influenza strains are nothing new and have not resulted in similar long-term slowdown in life expectancy improvement in the UK in previous decades. Further, most winters between 2011 and 2018 were warmer than the 1981-2010 average (https://bit.ly/2rc3IL1), and there was no influenza pandemic between 2011 and 2017.

In the absence of pandemics, natural disasters, war, or other major events that can directly affect vital statistics, an explanation based on of the social determinants of health approach appears to be relevant.[5] If social and economic factors determine the health of the population, then, it is these factors that we should be looking at when the health of the population deteriorates.[4] Of course, under this generic assumption, there is a very complex web of causation involving many interacting factors that awaits to be studied. Hiam and colleagues have made a strong case for public spending cuts and subsequent NHS and local authorities' underperformance being important parameters of the problem and highlighted the inability of the health and social care system to address the increased needs of the population, especially during the winter, and effectively support the elderly. $[10,19]$ It remains to be proven whether the suggested association between public spending cuts and the observed slowdown in life expectancy is causal. To this end, new pieces of the puzzle keep appearing $[17,20]$. An important new study suggests that between 2011 and 2016, life expectancy declined in women in the two most deprived IMD deciles (the estimated decline in women in the most deprived decile was 0.24 years), while it continued increasing in women at top IMD deciles (the estimated increase in women in the most affluent (tenth) decile was 0.38 years).[17] For the same period, life expectancy stalled for women in the third, fourth and fifth IMD deciles.[17] These findings not only draw a disconcerting picture of a society where poorer people no longer reap the benefits of a prosperous society, but importantly suggest that the problem of increased mortality and stalling life expectancy concerns more the poorest half of the population. Although clearly more research is needed on this key issue, the question follows: if the problem mostly concerns the poorer half of the population, should not the solution also mostly concern this part of the population?

The main criticism to an austerity explanation is that countries like Greece that implemented harsher austerity policies did not experience a slowdown in life expectancy as great as that in the UK. [1,12] While this needs to be studied further and may be due to different reasons, the bigger picture is that fluctuations in mortality and a slowdown in life expectancy in many European countries in the 2010s were preceded by the very severe 2008 financial crisis and the austerity policies that followed.[4]

Undoubtedly, we live in interesting times. It is the first time that life expectancy comes to a long-term halt in the UK. It is also the first time in at least fifty years that real median incomes in the UK have stagnated for 10 years and fallen below their historical growth rate to an unprecedented extent, while income inequalities and child poverty especially among workless households are on the rise [21] ...it is time to act.

Panayotes Demakakos, PhD

Department of Epidemiology and Public Health

University College London

1-19 Torrington Place

London, WC1E 6BT

Email:p.demakakos@ucl.ac.cuk 


\section{Declarations of interest: none}

Funding statement: This research did not receive any specific grant from funding agencies in the public, commercial, or not-for-profit sectors

\section{REFERENCES}

[1] Health at a Glance: Europe 2018. State of Health in the EU Cycle, OECD Publishing, Paris, 2018. doi:10.1787/health_glance_eur-2018-en.

[2] J.Y. Ho, A.S. Hendi, Recent trends in life expectancy across high income countries: retrospective observational study., BMJ. 362 (2018) k2562. doi:10.1136/bmj.k2562.

[3] S.L. Murphy, J. Xu, K.D. Kochanek, A. Elizabeth, Mortality in the United States, 2017, 2018. https://www.cdc.gov/nchs/data/databriefs/db328-h.pdf.

[4] M. Marmot, Social causes of the slowdown in health improvement., J. Epidemiol. Community Health. 72 (2018) 359-360. doi:10.1136/jech-2018-210580.

[5] L. Hiam, D. Dorling, M. McKee, The cuts and poor health: when and how can we say that one thing causes another?, J. R. Soc. Med. 111 (2018) 199-202.

doi:10.1177/0141076818779237.

[6] ONS, Changing trends in mortality in England and Wales: 1990 to 2017 (Experimental Statistics) - Office for National Statistics, 2018.

https://www.ons.gov.uk/peoplepopulationandcommunity/birthsdeathsandmarriages /deaths/articles/changingtrendsinmortalityinenglandandwales1990to2017/experime ntalstatistics (accessed 26 November 2018).

[7] National life tables, UK: 2015 to 2017 - Office for National Statistics, London, 2018. https://www.ons.gov.uk/peoplepopulationandcommunity/birthsdeathsandmarriages /lifeexpectancies/bulletins/nationallifetablesunitedkingdom/2015to2017 (accessed 28 November 2018).

[8] L. Hiam, D. Dorling, Rise in mortality in England and Wales in first seven weeks of 2018, BMJ. 360 (2018) k1090. doi:10.1136/bmj.k1090.

[9] D. Dorling, S. Gietel-Basten, Life expectancy in Britain has fallen so much that a million years of life could disappear by 2058 - why?, 2017.

https://theconversation.com/life-expectancy-in-britain-has-fallen-so-much-that-amillion-years-of-life-could-disappear-by-2058-why-88063 (accessed 04 December 2018).

[10] L. Hiam, D. Harrison, M. McKee, D. Dorling, Why is life expectancy in England and Wales "stalling"?, J. Epidemiol. Community Health. 72 (2018) 404-408. doi:10.1136/jech-2017-210401.

[11] Quarterly mortality, England - Office for National Statistics, 2018. https://www.ons.gov.uk/peoplepopulationandcommunity/birthsdeathsandmarriages /deaths/datasets/quarterlymortalityreportsanalysis (accessed 28 November 2018). 
[12] V.S. Raleigh, Stalling life expectancy in the UK, BMJ. 362 (2018) k4050. doi:10.1136/bmj.k4050.

[13] D. Taylor-Robinson, B. Barr, Death rate now rising in UK's poorest infants, BMJ. 357 (2017) j2258. doi:10.1136/bmj.j2258.

[14] Child mortality in England and Wales - Office for National Statistics, Stat. Bull. (2018). https://www.ons.gov.uk/peoplepopulationandcommunity/birthsdeathsandmarriages /deaths/bulletins/childhoodinfantandperinatalmortalityinenglandandwales/2016 (accessed 01 December 2018).

[15] Public Health England, Chapter 5: inequality in health - GOV.UK, 2017. https://www.gov.uk/government/publications/health-profile-for-england/chapter-5inequality-in-health (accessed 30 November 2018).

[16] Public Health England, Chapter 5: inequalities in health - GOV.UK, 2018. https://www.gov.uk/government/publications/health-profile-for-england2018/chapter-5-inequalities-in-health (accessed 30 November 2018).

[17] J.E. Bennett, J. Pearson-Stuttard, V. Kontis, S. Capewell, I. Wolfe, M. Ezzati, Contributions of diseases and injuries to widening life expectancy inequalities in England from 2001 to 2016: a population-based analysis of vital registration data, Lancet Public Heal. (2018). doi:10.1016/S2468-2667(18)30214-7.

[18] V.S. Raleigh, Why have improvements in mortality slowed down?, (2017). https://www.kingsfund.org.uk/blog/2017/11/improvements-mortality-slowed-down (accessed 29 November 2018).

[19] L. Hiam, D. Dorling, D. Harrison, M. McKee, What caused the spike in mortality in England and Wales in January 2015?, J. R. Soc. Med. 110 (2017) 131-137. doi:10.1177/0141076817693600.

[20] J. Watkins, W. Wulaningsih, C. Da Zhou, D.C. Marshall, G.D.C. Sylianteng, P.G. Dela Rosa, V.A. Miguel, R. Raine, L.P. King, M. Maruthappu, Effects of health and social care spending constraints on mortality in England: a time trend analysis., BMJ Open. 7 (2017) e017722. doi:10.1136/bmjopen-2017-017722.

[21] A. Hood, T. Waters, Living standards, poverty and inequality in the UK: 2017-18 to 2021-22, 2017. doi:10.1920/re.ifs.2017.0136. 